\title{
Perancangan dan Simulasi Prototype Saklar Pengatur Lampu Ruangan Berbasis Visual Basic 6.0 (Otomatis dan Manual)
}

\author{
Lia Kamelia, Edi Mulyana, Ibanez Valentino \\ Jurusan Teknik Elektro, Fakultas Sains dan Teknologi, Universitas Islam Negri Sunan Gunung Djati \\ Jl. A.H Nasution No. 105 Bandung \\ e-mail: liafandi79@gmail.com, edim@uinsgd.ac.id, Ibanez_kerenz91@yahoo.com,
}

\begin{abstract}
Abstrak - Saklar adalah sebuah perangkat yang digunakan untuk menghubungkan dan memutuskan jaringan listrik. Pada penelitian ini prototype saklar yang dibuat menggunakan program Visual Basic 6.0, dengan sistem kontrol secara manual maupun otomatis. Kemudian rangkaian dihubungkan ke PC menggunakan konektor db25. Penggunaan saklar secara manual yaitu dengan memilih tombol mana yang ingin dipilih pada program Visual Basic 6.0 yang telah dibuat, maka lampu simulasi yang saklarnya ada pada tombol tersebut menyala atau jika dipilih kembali tombol tersebut maka lampu simulasi akan padam. Dengan adanya saklar manual ini yang terdapat pada program Visual Basic 6.0, akan mempermudah mengontrol penggunaan lampu disuatu ruangan, dan menghidupkan/memadamkan lampu simulasi dengan saklar yang saling berdampingan. Sedangkan untuk penggunaan secara otomatis yaitu dengan memilih tombol otomatis,maka secara otomatis lampu akan menyala dengan sendirinya sesuai jadwal yang telah dibuat. Hasil pengujian baik secara manual maupun otomatis diperoleh beberapa kesimpulan. Kesimpulan pertama Prototype simulasi saklar lampu yang bisa dikendalikan secara otomatis melalui PC berbasis visual basic telah dibuat dan berhasil mengendalikan lampu led, yang kedua pembuatan sintak program menggunakan Visual basic yang dibuat dengan 2 tipe pengontrolan, manual dan otomatis. Dan yang terakhir pengujian program dilakukan dengan simulasi menggunakan miniatur ruangan yang dikoneksikan ke PC melalui konektor db25. Dengan adanya penggunaan saklar otomatis yang terdapat pada program Visual Basic 6.0 ini, akan mengefesiensi waktu saat menyalakan lampu diruangan yang banyak.
\end{abstract}

Kata Kunci: Saklar, otomatis, manual, Visual basic 6.0, db 25.

\section{Pendahuluan}

Saat ini perkembangan teknologi sangat berkembang pesat, teknologi dapat mempermudah, mengefisienkan dan mempercepat segala aktifitas manusia. Untuk itulah diperlukannya hardware dan software yang memadai untuk menunjang segala aktifitas manusia di zaman modern ini.

Saat ini pengontrolan lampu terbagi menjadi 2, manual dan otomatis. Sistem manual dapat ditemui pada saklar lampu ruangan, baik rumah maupun gedung bertingkat. Sementara sistem otomatis dapat ditemui pada lampu lalu lintas, lampu penerangan jalan dsb. Melihat saat ini pengontrolan lampu ruangan masih menggunakan sistem manual, dan belum adanya sistem otomatis sehingga menimbulkan berbagai masalah. Masalah yang sering terjadi, disuatu gedung yang memiliki banyak ruangan, ketika harus mematikan atau menyalakan lampu secara manual maka akan sangat menyita waktu. Selain itu faktor kelalaian bisa saja terjadi, seperti lupa mematikan atau menyalakan lampu sebuah ruangan sehingga pemakaian lampu tidak efisien dan tidak terkontrol.

Untuk mengatasi permasalahan ini dibutuhkanlah saklar pengatur lampu ruangan baik secara manual maupun otomatis, yang bisa diakses melalui PC dan dapat dikontrol pemakaian lampu tiap ruangannya. Pada perancangan prototype ini, software visual basic dibuat menjadi

TELKA, Vol.2, No.1, Mei 2016, pp. 1 9

ISSN: 2502-1982 
simulasi dari tombol-tombol saklar diruangan yang bisa dikendalikan secara manual maupun secara otomatis berdasarkan waktu yang telah disesuaikan menurut jadwal.

Sebuah PC dijadikan sebagai server, yang berguna sebagai saklar pengatur lampu baik secara manual maupun otomatis berdasarkan waktu. Sehingga lampu di tiap ruangan dapat dipantau melalui layar di PC. Sistem kerja dari prototype ini adalah software visual basic yang telah diprogram sebagai saklar pengatur lampu, dikoneksikan melalui sebuah konektor dari PC ke rangkaian led. Ketika tombol simulasi saklar disoftware visual basic ditekan, maka lampu dirangkaian led akan menyala sesuai tombol yang ditekan. Begitu juga saat pengontrolan sistem otomatis, lampu akan menyala berdasarkan waktu yang telah dijadwalkan di PC.

Software yang digunakan dalam penelitian ini adalah visual basic 6.0. Visual basic digunakan karena memiliki kelebihan dibanding bahasa pemrograman yang lain. Kelebihan visual basic adalah bahasa pemrogramannya yang singkat dan sederhana, banyak sumbersumber yang dapat digunakan untuk mempelajarinya, dan kompiler yang lebih cepat dibanding bahasa pemrograman yang lain seperti Delphi, Java, dan bahasa c.[7]

Sistem pengontrolan dari prototype ini sangat berguna, berapapun lampu ruangan yang dinyalakan atau dipadamkan, hanya perlu mengontrolnya menggunakan sebuah PC. Perancangan saklar lampu ruangan otomatis menggunakan software visual basic ini sangat cocok digunakan di gedung yang memiliki banyak lantai dan ruangan. Karena akan menghemat waktu dalam pengoperasiannya serta dapat mengontrol pemakaian lampu tiap ruangan hanya dari sebuah PC.

Pada prototype penelitian ini menggunakan 8 buah lampu led sebagai simulasi dari lampu ruangan, yang dikoneksikan dengan PC sebagai servernya. Selain itu prototype ini menggunakan contoh simulasi sistem pengontrolan dari sebuah rumah, karena untuk memudahkan dalam pengujian dan pembuatan simulasi. Selain itu juga karena lampu pada sebuah rumah menggunakan lampu yang lebih sedikit dari sebuah gedung, sehingga dapat menghemat biaya dan waktu dalam pengerjaannya.

Pembuatan prototype ini bisa menjadi solusi dimasa depan untuk memudahkan dalam pengontrolan lampu di sebuah gedung yang banyak ruangannya. Selain ini prototype ini kedepannya bisa dikembangkan agar lebih sempurna sehingga lebih berguna pemakaiannya.

Tujuan dari penelitian ini adalah :

1. Membuat simulasi saklar lampu yang bisa dikendalikan secara otomatis melalui PC berbasis visual basic.

2. Membuat sintak program program saklar lampu menggunakan visual basic.

Melakukan pengujian data pemrograman saklar pengatur lampu ke rangkaian lampu LED sebagai simulasi.

\section{Metodologi Penelitian}

\subsection{Analisis Kebutuhan}

Tahap ini, pertama-tama menganalisis kebutuhan apa saja yang dibutuhkan untuk membuat saklar pengatur lampu ruangan berbasis visual basic 6.0 (secara otomatis dan manual). Kebutuhan dalam penelitian ini melingkupi hardware dan software. Kebutuhannya antara lain : HARDWARE

1. Solder listrik

2. Timah

3. Lem Power

4. Duplex

5. Cutter

6. Kabel

7. Lampu led 8 buah

8. Resistor 8 buah

9. Konektor db25 male 
10. PCB

11. PC

SOFTWARE

Visual Basic 6.0

\section{2. Perancangan}

Pada tahap ini dilakukan perancangan alat untuk membuat simulasi. Perancangan dimulai dengan membuat miniatur ruangan pada sebuah rumah. Miniatur ini berguna untuk membuat simulasi dari pengatur lampu berbasis visual basic 6.0, baik secara otomatis dan manual. Selain itu juga merancang rangkaian yang dibutuhkan dalam pembuatan simulasi mengguanakan visual basic 6.0.

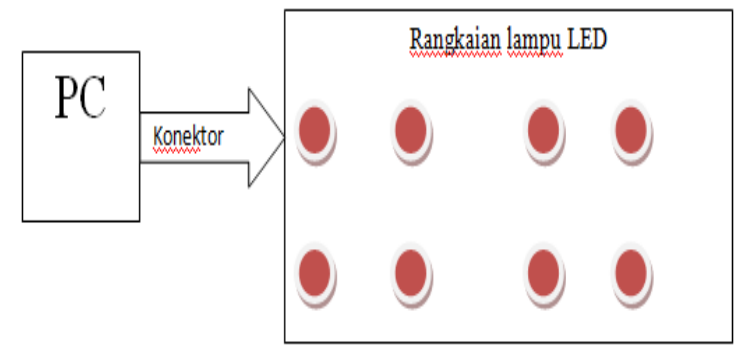

Gambar 1. Blok diagram saklar pengatur lampu berbasis visual basic

Perancangan yang akan dilakukan terbagi menjadi 3 langkah, yaitu :

a. Perancangan Rangkaian

Terdapat beberapa tahap dalam perancangan ini yang harus dibuat, yaitu :

1. Pembuatan rangkaian LED

2. Pembuatan miniatur ruangan

b. Perancangan program (coding)

Terdapat beberapa tahap dalam perancangan ini yang harus dilakukan, yaitu :

1. Pembuatan program pengatur lampu sistem manual.

2. Pembuatan program pengatur lampu sistem otomatis berdasar waktu yang telah dijadwalkan.

c. Pembuatan Skenario pengujian

Terdapat beberapa perancangan skenario dalam pengujian, yaitu :

1. Skenario pertama membuat semua lampu LED menyala secara manual.

2. Skenario kedua membuat semua lampu LED padam secara manual.

3. Skenario ketiga membuat beberapa lampu menyala sesuai jadwal.

4. Skenario keempat membuat semua lampu LED padam secara otomatis sesuai jadwal.

5. Skenario kelima membuat lampu led menyala secara otomatis sesuai jadwal.

\subsection{Perakitan}

Tahap selanjutnya adalah perakitan, pada tahap ini yang harus dilakukan adalah merakit apa yang sudah dirancang kedalam PCB. Semua komponen dirakit sesuai dengan rancangan yang sudah dibuat. Selain membuat rangkaian juga membuat program simulasi untuk pengujian.

\subsection{Pengujian}

Setelah rangkaian dan program selesai dibuat, pada tahap ini dilakukan pengujian dan pengukuran. Pengujian dilakukan untuk mengetahui apakah ada kesalahan pada saat membuat rangkaian dan program, jika ada kesalahan dalam membuat rangkaian dan program maka dilakukan penyempurnaan.

Pengujian yang dilakukan adalah :

1. Pengujian secara manual

Pada pengujian ini dilakukan dengan sistem manual, yaitu tiap lampu dinyalakan secara manual dengan menekan tombol pada program di PC. 
2. Pengujian secara otomatis

Pada pengujian ini dilakukan dengan sistem otomatis, yaitu lampu akan menyala otomatis sesuai jadwal yang sudah disesuaikan.

\subsection{Analisis Pengujian}

Setelah melakukan tahap pengujian, maka akan diketahui kesalahan-kesalahan yang terjadi. Ketika kesalahan terjadi maka yang harus dilakukan adalah menganalisis. Tahap ini bertujuan agar kesalahan yang terjadi dapat dicari solusinya agar hasilnya sesuai yang diinginkan.

\subsection{Perbaikan dan penyempurnaan}

Perbaikan dan penyempurnaan bertujuan agar hasil yang didapatkan sesuai yang diinginkan. Jika perbaikan kesalahan sudah dilakukan maka diharapkan tidak ditemukan lagi kesalahan kedepannya dalam menyelesaikan penelitian ini.

\section{Pembahasan dan Hasil}

Perancangan perangkat prototype simulasi saklar lampu manual dan otomatis berbasis visual basic 6.0 memiliki skema pada gambar 2 .

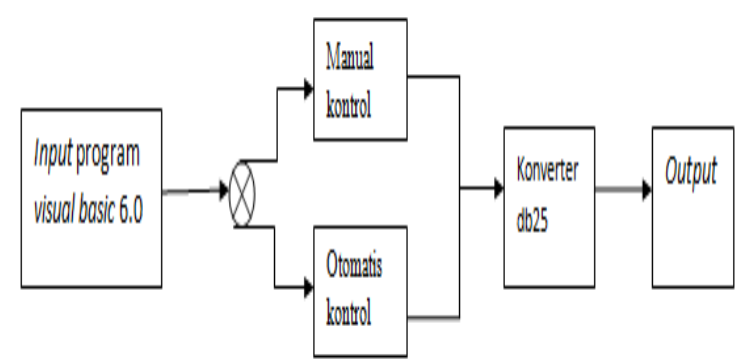

Gambar 2. diagram blok prototype simulasi saklar lampu berbasis visual basic 6.0

\subsection{Perancangan Hardware}

Pada proses perancangan hardware meliputi skema rangkaian, membuat rangkaian prototype saklar lampu berbasis visual basic 6.0 dan pembuatan miniatur ruangan yang digunakan sebagai simulasi saklar pengatur lampu ruangan berbasis visual basic 6.0. Perancangan dan pembuatan hardware ini bertujuan untuk mengetes apakah sesuai dengan yang diinginkan dan tidak mengalami error.

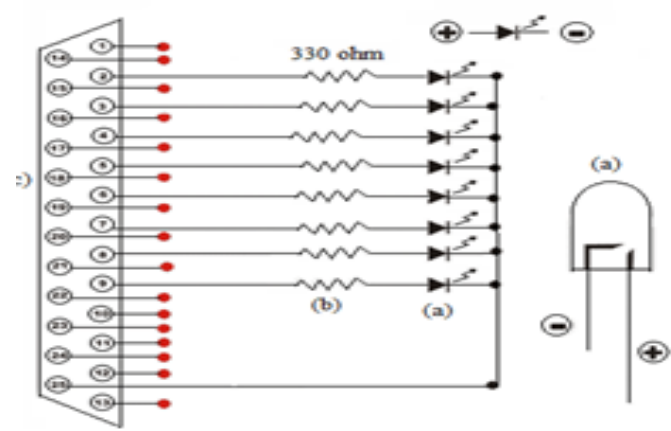

Gambar 3. Skema rangkaian simulasi saklar lampu

Keterangan pada gambar 3:
a. Led (Led yang dipasang berjumlah 8 buah).
b. Resistor.
c. Konektor db25. 


\subsubsection{Membuat rangkaian prototype saklar lampu}

Pada tahap ini adalah membuat prototype rangkaian led yang digunakan sebagai output. Disini juga dibuat konektor antara db25 dan PC, karena konektor ini sangat penting agar bisa mengetes apakah program dan rangkaian yang telah dibuat sudah benar atau mengalami error.

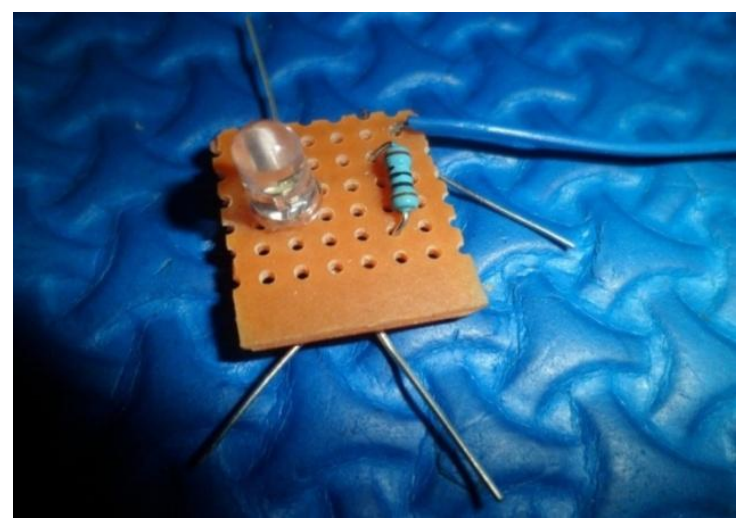

Gambar 4. Rangkaian led

Tabel 1 merupakan daftar susunan rangkaian dari skema rangkaian led:

Tabel 1. Tabel Skema Susunan Rangkaian

\begin{tabular}{|c|c|c|}
\hline PORT PIN DB25 & LAMPU LED & FUNGSI \\
\hline 2 & 1 & Pintu utama \\
\hline 3 & 2 & Garasi \\
\hline 4 & 3 & Ruang tamu \\
\hline 5 & 4 & Kamar 2 \\
\hline 6 & 5 & Kamar 1 \\
\hline 7 & 6 & Ruang Tengah \\
\hline 8 & 7 & Toilet \\
\hline 9 & 8 & Ruang belakang \\
\hline 25 & - & Ground \\
\hline
\end{tabular}

\subsubsection{Membuat Miniatur Ruangan}

Setelah membuat rangkaian led yang terhubung kekonektor db25, langkah selanjutnya adalah membuat miniatur ruangan yang akan digunakan sebagai simulasi saklar lampu. Miniatur ini dibuat menggunakan duplex, sejenis karton tebal yang sering digunakan untuk membuat maket. 


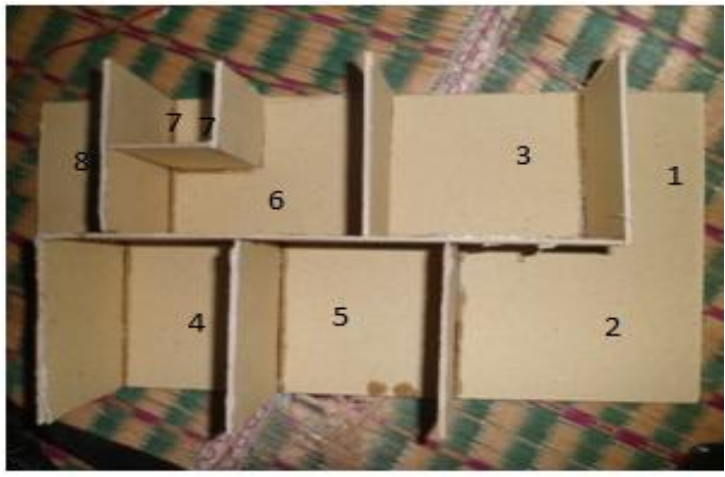

Gambar 5. Miniatur ruangan

Gambar 5 adalah gambar dari miniatur ruangan yang belum dipasangi rangkaian led. Ruangan yang dibuat sesuai gambar pada software visual basic yang telah dibuat sebagai acuan utama. Ruangan yang dibuat adalah (1) pintu utama, (2) garasi, (3) ruang tamu, (5) kamar 2, (4) kamar 1, (6) ruang tengah, (7) toilet dan (8) ruang belakang.

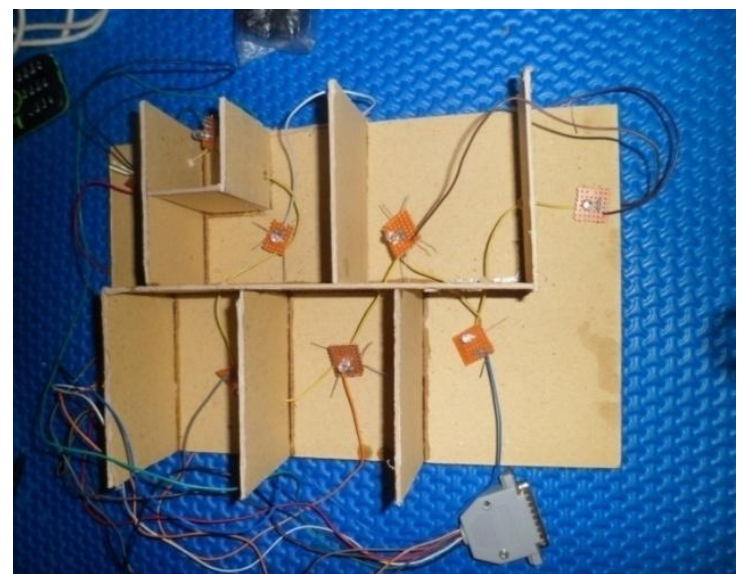

Gambar 6. Miniatur ruangan yang terpasang rangkaian led

Setelah membuat komponen yang dirangkai pada PCB bolong dan membuat miniatur ruangan, selanjutnya memasangkan rangkaian led keminiatur ruangan yang akan digunakan sebagai simulasi. Pemasangan rangkaian led ke miniatur dapat dilihat pada gambar 6 .

\subsection{Perancangan Software}

Perancangan software ini bertujuan untuk menampilkan program dari protoype simulasi saklar lampu menggunakan visual basic 6.0. Pada saat program dijalankan maka akan muncul form menu dari program, yang digunakan sebagai simulasi saklar lampu. Pada tahap ini meliputi pembuatan program dan membuat module visual basic 6.0.

Skenario dari perancangan software dibagi menjadi 2, manual dan otomatis. Untuk manual software yang dirancang adalah pintu utama, garasi, ruang tamu, kamar 2, kamar1, ruang tengah, toilet, dan lampu belakang rumah. Untuk sistem otomatis dibuat menjadi 5 jadwal. Jadwal bisa dilihat pada tabel 2 . 
Tabel 2. skenario perancangan penjadwalan sistem otomatis

\begin{tabular}{|c|l|l|}
\hline Penjadwalan & \multicolumn{1}{|c|}{ Waktu } & \multicolumn{1}{c|}{ Status Lampu } \\
\hline 1 & $\begin{array}{l}\text { Setiap hari 17.30- } \\
06.00\end{array}$ & Semua lampu menyala \\
\hline 2 & $\begin{array}{l}\text { Senin s/d jum'at } \\
06.00-17.00\end{array}$ & Semua lampu padam \\
\hline 3 & $\begin{array}{l}\text { Setiap hari 17.00- } \\
17.30\end{array}$ & $\begin{array}{l}\text { Pintu utama, garasi, ruang tengah, toilet, dan ruang } \\
\text { belakang menyala }\end{array}$ \\
\hline 4 & $\begin{array}{l}\text { Sabtu dan minggu } \\
\text { Ruang tamu, kamar2, kamar 1, ruang tengah, dan toilet } \\
\text { menyala }\end{array}$ \\
\hline 5 & $\begin{array}{l}\text { Sabtu dan minggu } \\
10.00-17.00 ~\end{array}$ & Semua lampu padam \\
\hline
\end{tabular}

Tabel 2 menjelaskan tentang perancangan penjadwalan otomatis lampu berdasarkan waktu. Pada penjadwalan 1 setiap hari jam 17.30-06.00 maka semua lampu menyala. Penjadwalan 2, senin s/d jum'at pada jam 06.00-17.00 maka semua lampu akan padam. Pada penjadwalan 3, setiap hari 17.00-17.30 pintu utama, garasi, ruang tengah, toilet dan ruang belakang akan menyala. Penjadwalan 4 sabtu minggu jam 08.00-10.00 ruang tamu, kamar 2, kamar 1, ruang tengah dan toilet menyala. Dan pada penjadwalan terakhir sabtu minggu 10.00-17.00 semua lampu akan padam.

\subsection{Hasil penelitian}

Pada pengujian manual ini dilakukan beberapa kali pengujian untuk mengetahui apakah ada lampu yang menyala atau tidak.

Tabel 3. Data Pengujian simulasi manual

\begin{tabular}{|c|c|c|c|}
\hline Pengujian & Lampu Led & Status & $\begin{array}{c}\text { Delay saat } \\
\text { Menyala }\end{array}$ \\
\hline 1 & $1,2,3,4,5,6,7,8$ & Bergantian & 1 detik \\
\hline 2 & $1,2,3,4,5,6,7,8$ & Bersamaan & 4 detik \\
\hline 3 & $1,2,3,4$ & Bergantian & 1 detik \\
\hline 4 & $1,2,3,4$ & Bersamaan & 2 detik \\
\hline 5 & $5,6,7,8$ & Bergantian & 1 detik \\
\hline 6 & $5,6,7,8$ & Bersamaan & 2 detik \\
\hline
\end{tabular}

Tabel 4. data pengujian simulasi otomatis

\begin{tabular}{|c|c|l|c|}
\hline Pengujian & Penjadwalan & \multicolumn{1}{|c|}{ Status } & Delay lampu \\
\hline 1 & 1 & Semua lampu menyala & 1 detik \\
\hline 2 & 2 & Semua lampu padam & 1 detik \\
\hline 3 & 3 & $\begin{array}{l}\text { Pintu utama, garasi, } \\
\text { ruang tengah, toilet, } \\
\text { ruang belakang } \\
\text { menyala }\end{array}$ & 1 detik \\
\hline 4 & 4 & $\begin{array}{l}\text { Ruang tamu, Kamar 2, } \\
\text { Kamar 1, Ruang } \\
\text { tengah,Toilet menyala }\end{array}$ & 1 detik \\
\hline 5 & 5 & Semua Lampu Padam & 1 detik \\
\hline
\end{tabular}


Dari data tabel 4 diperoleh data bahwa lampu akan menyala atau padam sesuai dengan jadwal yang telah dibuat. Jeda waktu antara menyala dan padam adalah 1 detik, walaupun dengan semua lampu menyala bersamaan. Jeda waktu yang hanya 1 detik karena lampu tidak dinyalakan secara manual yang tergantung pada kecepatan tangan dari operator.

Dari pengujian secara manual dan otomatis maka diketahui adanya perbedaan waktu delay lampu antara manual dan otomatis. Pada sistem manual sangat tergantung dari kecepatan tangan operator saat menyalakan lampu, sementara otomatis tidak dipengaruhi oleh kecepatan tangan dari operator karena lampu akan menyala sesuai jadwal yang telah dibuat.

\section{Kesimpulan dan Saran}

4.1 Kesimpulan

Berdasarkan penelitian yang telah dilakukan maka diperoleh kesimpulan sebagai berikut :

1. Prototype simulasi saklar lampu yang bisa dikendalikan secara otomatis melalui PC berbasis visual basic telah dibuat dan berhasil mengendalikan lampu led.

2. Pembuatan sintak progam menggunakan visual basic yang dibuat dengan 2 tipe pengontrolan, manual dan otomatis.

3. Pengujian program dilakukan dengan simulasi menggunakan miniatur ruangan yang dikoneksikan ke PC melalui konektor db25.

\subsection{Saran}

Beberapa saran untuk pengembangan alat sebenarnya sebagai berikut :

1. Konektor db25 pada PC bisa diubah ke usb untuk kemudahan dalam konektifitasnya. Selain itu juga perlu diperiksanya PC apakah ada port db25, karena port ini yang penting digunakan untuk konektor antara rangkaian led dan PC.

2. Port db25 bisa diganti dengan koneksi wifi untuk gedung yang berada dalam 1 komplek.

\section{Daftar Pustaka}

[1] Lou Tylee. Course Notes for: Learn Visual Basic 6.0, KIDware, 1998

[2] Sue Sentance, Steven Johnston, Steve Hodges, Jan Kučera, James Scott, Scarlet

Schwiderski-Grosche. Learning To Program With Visual Basic And .Net Gadgeteer.

Creative Commons Attribution-ShareAlike 3.0. California, 2013

[3] Fabian Winkler. Basics of Electricity/Electronics. http://www.cla.purdue.edu/vpa/etb/. 2010

[4] Al-Mubarok, N.H. Otomastisasi Penerangan Pada Gedung Perkantoran Berbasis Personal Komputer Menggunakan Bahasa Pemrograman Delphi. Jurnal Teknik Elektro vol.2 No.2, 2010

[5] Andi, Mahir Dalam 7 Hari Microsoft Visual Basic 6.0. Madcoms Madiun. Yogyakarta, 2010 .

[6] Aziz, M.A. Kontrol Lampu Gedung Bertingkat Berbasis Berbasis Personal Computer (PC). Jurnal Neutrino Vol. 1 No.2, 2009.

[7] Basuki, A. Algoritma Pemrograman 2 Menggunakan Visual Basic 6.0. Institut Teknologi Sepuluh November. Surabaya, 2006.

[8] Junaedi, I. dan Herlinawati. Perancangan dan Realisasi Pengaturan Lampu Rumah Tinggal Melalui Saluran Telepon Menggunakan Pengendali Mikro At89c2051r, 2007.

[9] Krisna D.O. Cepat Mahir Visual Basic 6.0. Kuliah Berseri IlmuKomputer.com., 2003.

[10] Kurniadi, A. Pemrograman Microsoft Visual basic 6. Elex Media Komputindo. Jakarta, 2003.

[11] Lajanto, D. Sistem Kendali Umpan Balik Pada Lampu Berbasis) Short Message Service (SMS). Universitas Tanjungpura. 
[12] Rengga, P. Otomatisai Lampu Rumah Menggunakan Timer dan PWM Untuk Pengaturan Intensitas Cahaya Berbasis Mikrokontroler ATMEGA32, 2013.

[13] Rusmawan, U. Visual Basic 6.0 Untuk Semua Tingkatan. Elex Media Komputondo. Jakarta, 2011.

[14] Supatmi, S. Simulasi Pengontrol Lampu Gedung Menggunakan Visual Basic. Seminar Nasional Informatika. Yogyakarta, 2010. 